\title{
Last Menstrual Period
}

National Cancer Institute

\section{Source}

National Cancer Institute. Last Menstrual Period. NCI Thesaurus. Code C81257.

The first day of the female's last menstrual cycle. 